\title{
Proctitis in homosexual men
}

\section{A diagnostic problem}

\author{
A McMillan,* H M GilmoUR,† K SlAtFord,* AND G J C McNeillage* \\ From the *University Department of Genitourinary Medicine, Edinburgh Royal Infirmary, and the \\ †Department of Pathology, University of Edinburgh, Edinburgh
}

SUMMARY One hundred and seventy six men with histories of anal intercourse were studied to $\overrightarrow{\omega^{\circ}}$ determine if there was a correlation between the clinical features, cytological findings in theos mucosal secretions, and the histological appearance of the rectal mucosa. The presence or absence of gastrointestinal symptoms did not differentiate between patients with and without proctitis. Sigmoidoscopy was normal in each of the 117 men with normal rectal histology. Macroscopicin abnormalities were evident in the mucosa of nine of 11 men with infective proctitis, ando sigmoidoscopy was normal in $\mathbf{4 0}$ of the $\mathbf{4 8}$ men with chronic proctitis. Cytological examination 9 was often useful in detecting infective proctitis but not chronic proctitis.

\section{Introduction}

The number of men who attend sexually transmitted diseases (STD) clinics and give a history of homosexual contact, including anal intercourse, is increasing. ${ }^{1}$ It is therefore important that doctors working in genitourinary medicine should be aware of the various anorectal disorders from which these men may suffer.

Inflammatory changes in the rectal mucosa may result from infection with bacteria, viruses, or protozoa, ${ }^{2}$ and there is a group of patients with proctitis in whom an aetiological agent cannot be identified (non-specific proctitis). The criteria for diagnosing proctitis vary widely, ${ }^{3}$ and results from different centres may not be comparable. Histological examination of rectal biopsy specimens is the most reliable method of establishing a diagnosis of proctitis; but as cytological examination of mucosal secretions correlates well with the histological findings in patients with ulcerative proctocolitis, ${ }^{4}$ we decided to investigate its usefulness in diagnosing proctitis in homosexual men.

\section{Patients and methods}

The study was approved by the ethics committee of the South Lothian District of the Lothian Health Board.

Address for reprints: Dr A McMillan, Department of Genitourinary Medicine, Royal Infirmary, Edinburgh EH3 9YW

Accepted for publication 14 January 1983
One hundred and seventy six men (mean age $26 \cdot 2 \frac{2}{\omega}$ years; range 17 to 63 years) who attended consecutively the department of genitourinary ${ }_{\infty}$ medicine, Edinburgh Royal Infirmary, as new or ${ }^{\omega}$ "return new" patients and who gave a history of homosexual anal intercourse were studied. Men who had received antibiotic treatment within the preceding few weeks were excluded. A careful history, which included specific questions about the occurrence of diarrhoea (defined as the passage of at $\overrightarrow{\overrightarrow{7}}$ least three unformed stools during 24 hours), $\frac{9}{3}$ pruritus ani, and anal discharge or bleeding within the preceding 28 days, was obtained from eachọ. patient. After general physical examination a plastic disposable proctoscope (Welch Allen Ltd, UK), lightly lubricated with KY jelly (Johnson and Johnson, UK), was passed through the anal canal and the obturator withdrawn.

The macroscopic appearance of the rectal mucosa was recorded according to the system of Watts et al. ${ }^{4}$ 금 The presence or absence of the normal vascular $\frac{D}{O}$ pattern, oedema, contact bleeding, and ulceration were noted; the appearance of the mucosa was $\tilde{N}$ considered abnormal if at least one abnormal feature $\mathrm{N}$ was present. After a rectal impression smear had been prepared and material collected for ${ }^{\omega}$ microbiological examination as described elsewhere sigmoidoscopy was performed and a biopsy speciment? taken from the site at which the impression smear had been obtained.

HISTOLOGY

The biopsy specimens were fixed in formol saline and processed in the usual manner. Sections cut at 3-4 $\mu \mathrm{m}$ 응 
were stained with haematoxylin and eosin and examined by one of us (HMG) who was not aware of the clinical and cytological findings. Histological changes were graded as described by Dickinson $e t$ $a l^{6}$ : grade A-normal; grade B (chronic proctitis)-a mild to moderate excess of chronic inflammatory cells in the lamina propria; and grade $C$ (infective proctitis) - a predominantly acute inflammatory cell filtrate in the superficial lamina propria with the migration of polymorphonuclear leucocytes through the crypt epithelium. These changes are not those typically associated with ulcerative colitis or Crohn's disease.

\section{CYTOLOGICAL PREPARATIONS}

Material for cytological examination was collected by a modification of the method of Anthonisen and Riis. ${ }^{7}$ A $13 \mathrm{~mm}$ circular coverslip was mounted by means of a piece of Blu-Tack (Bostik Ltd, Leicester, UK) on to a cork with a base diameter of $13 \mathrm{~mm}$. The cork was attached to a dissecting needle $12 \mathrm{~cm}$ in length and together with the coverslip was passed through the proctoscope until contact was made with the mucosa. After 10 seconds the apparatus was withdrawn and the cork and coverslip were detached from the needle and placed, coverslip down, in a small Petri dish containing absolute methanol. After fixation for 10 minutes the smear was stained by Giemsa and the coverslip mounted in DPX. The stained smears were examined by a Zeiss large universal microscope. As calculated by the stage micrometer, an area of $0.64 \mathrm{~cm}^{2}$ was examined, and the numbers of polymorphonuclear leucocytes and lymphocytes within this area were counted.

\section{STATISTICAL ANALYSES}

To evaluate the correlation between the cytological and histological findings the Kruskal-Wallis one way analysis of variance by ranks and the Wilcoxon rank tests were used. The $\chi^{2}$ test with Yates's correction was used in the analysis of the clinical features.

\section{Results}

Table I indicates the diagnoses made in the 176 patients studied, 17 of whom were found to have more than one infection. At least one sexually transmitted disease had previously been diagnosed in 137 men, 54 having had more than one disease (table II).

\section{HISTOLOGICAL FINDINGS}

The histology of the rectal mucosa was normal (grade A) in 117 men and showed the pattern of chronic proctitis (grade B) in $\mathbf{4 8}$ men and that of infective proctitis (grade C) in 11 men (table III).

TABLE I Diagnoses made in the 176 homosexual men studied

\begin{tabular}{lc}
\hline Diagnosis* & $\begin{array}{l}\text { No of men } \\
\text { affected }\end{array}$ \\
\hline Early syphilis & 8 \\
Gonorrhoea & \\
$\quad$ Urethral & 10 \\
Rectal & 22 \\
Pharyngeal & 6 \\
Non-gonococcal urethritis & 9 \\
Rectal chlamydial infection & 2 \\
Anorectal herpes simplex & 5 \\
Anorectal warts & 2 \\
Amoebiasis & 9 \\
Giardiasis & 8 \\
Enterobiasis & 6 \\
Chronic hepatitis B & 5 \\
Shigellosis & 1 \\
No detectable infection & 105 \\
\hline
\end{tabular}

*More than one infection was diagnosed in 17 men.

TABLE II Past history of sexually transmissible diseases in the 176 homosexual men studied

\begin{tabular}{lc}
\hline Disease & No of men previously affected* \\
\hline Early syphilis & 11 \\
Gonorrhoea & 42 \\
Urethral & 30 \\
Rectal & 6 \\
Pharyngeal & 35 \\
Non-gonococcal urethritis & 6 \\
Anogenital herpes simplex & 26 \\
Anogenital warts & 3 \\
Hepatitis A & 10 \\
Hepatitis B & 2 \\
Giardiasis & 60 \\
Pthiriasis & 8 \\
Scabies & 39 \\
No previous infection & \\
\hline *54 men had been affected previously with two or more diseases.
\end{tabular}

TABLE III Symptoms and histological grading of the rectal mucosa in the 176 homosexual men studied

\begin{tabular}{|c|c|c|c|c|c|}
\hline \multirow[b]{2}{*}{$\begin{array}{l}\text { Histological grading† } \\
\text { of rectal biopsy specimen }\end{array}$} & \multicolumn{4}{|c|}{ No $(\%)$ of men* presenting with: } & \multirow{2}{*}{$\begin{array}{l}\text { Total No } \\
\text { of men } \\
\text { in each } \\
\text { group }\end{array}$} \\
\hline & Diarrhoea & $\begin{array}{l}\text { Pruritus } \\
\text { ani }\end{array}$ & $\begin{array}{l}\text { Anal } \\
\text { discharge }\end{array}$ & $\begin{array}{l}\text { Anorectal } \\
\text { bleeding }\end{array}$ & \\
\hline $\begin{array}{l}\text { A: normal histology } \\
\text { B: chronic proctitis } \\
\text { C: infective proctitis }\end{array}$ & $\begin{array}{r}22(18 \cdot 8) \\
7(14 \cdot 6) \\
3(27 \cdot 3)\end{array}$ & $\begin{array}{r}20(17 \cdot 1) \\
12(25 \cdot 0) \\
3(27 \cdot 3)\end{array}$ & $\begin{array}{l}9(7 \cdot 7) \\
7(14 \cdot 6) \\
4(36 \cdot 4)\end{array}$ & $\begin{array}{r}12(10 \cdot 3) \\
9(18 \cdot 8) \\
1(9 \cdot 1)\end{array}$ & $\begin{array}{r}117 \\
48 \\
11\end{array}$ \\
\hline
\end{tabular}

*Some men had more than one symptom.

tSee text for details. 
Table IV summarises the rectal histology in patients in whom a gastrointestinal infection was diagnosed. An infective cause for the proctitis could be found in $18(37.5 \%)$ men and five $(45.5 \%)$ men whose rectal histology was graded $B$ and $C$ respectively.

TABLE IV Anorectal infections in relation to the histological findings in the rectum of 176 homosexual men

\begin{tabular}{|c|c|c|c|c|}
\hline \multirow[b]{2}{*}{ Infection } & \multirow{2}{*}{$\begin{array}{l}\text { No of men } \\
\text { affected }\end{array}$} & \multicolumn{3}{|c|}{$\begin{array}{l}\text { Histological grading } \\
\text { of rectal mucosa }\end{array}$} \\
\hline & & $\boldsymbol{A}$ & $\boldsymbol{B}$ & $C$ \\
\hline Early syphilis & 8 & 4 & 3 & 1 \\
\hline Rectal gonorrhoea & 22 & 12 & 7 & 3 \\
\hline Amoebiasis & 9 & 4 & 5 & 0 \\
\hline Rectal herpes simplex & 5 & 4 & 1 & 0 \\
\hline \multicolumn{5}{|l|}{ Rectal chlamydial infection: } \\
\hline With gonorrhoea & 1 & 0 & 1 & 0 \\
\hline With amoebiasis & 1 & 0 & 1 & 0 \\
\hline Shigellosis & 1 & 0 & 0 & 1 \\
\hline
\end{tabular}

$A=$ normal histology; $B=$ chronic proctitis; $C=$ infective proctitis.

\section{SYMPTOMS}

Forty two $(35 \cdot 9 \%)$ of the 117 men whose rectal biopsy specimens showed a normal (grade A) histological appearance reported at least one symptom (mean duration $\mathbf{2 \cdot 2}$ weeks, range three days to 19 weeks) referable to the gastrointestinal tract (table III). Similar symptoms were noted in 19 $(39 \cdot 6 \%)$ and eight $(72 \cdot 7 \%)$ patients whose histological changes were graded B and C respectively; the mean duration of symptoms in these two groups of patients was 2.0 weeks (range 5 days to 15 weeks) and 2.6 weeks (range 5 days to 12 weeks) respectively. There were no significant differences between the prevalence of symptoms in patients with grade $A$ and $B$ changes and those with grade $B$ and $C$ changes $\left(\chi^{2}=0.072, p>0.5\right.$ and $\chi^{2}=2 \cdot 738, \mathrm{p}>0.05$ respectively). Symptoms were, however, reported significantly more frequently by patients with grade $\mathbf{C}$ changes than by those whose rectal histology was normal $\left(\chi^{2}=4 \cdot 287 ; p<0 \cdot 05\right)$.

\section{SIGMOIDOSCOPIC FINDINGS}

The sigmoidoscopic appearance of the rectal mucosa was normal in each of the patients whose rectal histology was normal. The macroscopic appearance of the mucosa was abnormal in eight of the $\mathbf{4 8}$ men with grade $B$ histological changes and was normal in only two of the 11 men with grade $C$ changes.

\section{CYTOLOGICAL FINDINGS}

The figure shows the numbers of polymorphonuclear leucocytes and lymphocytes found within the defined area of the stained impression smear.
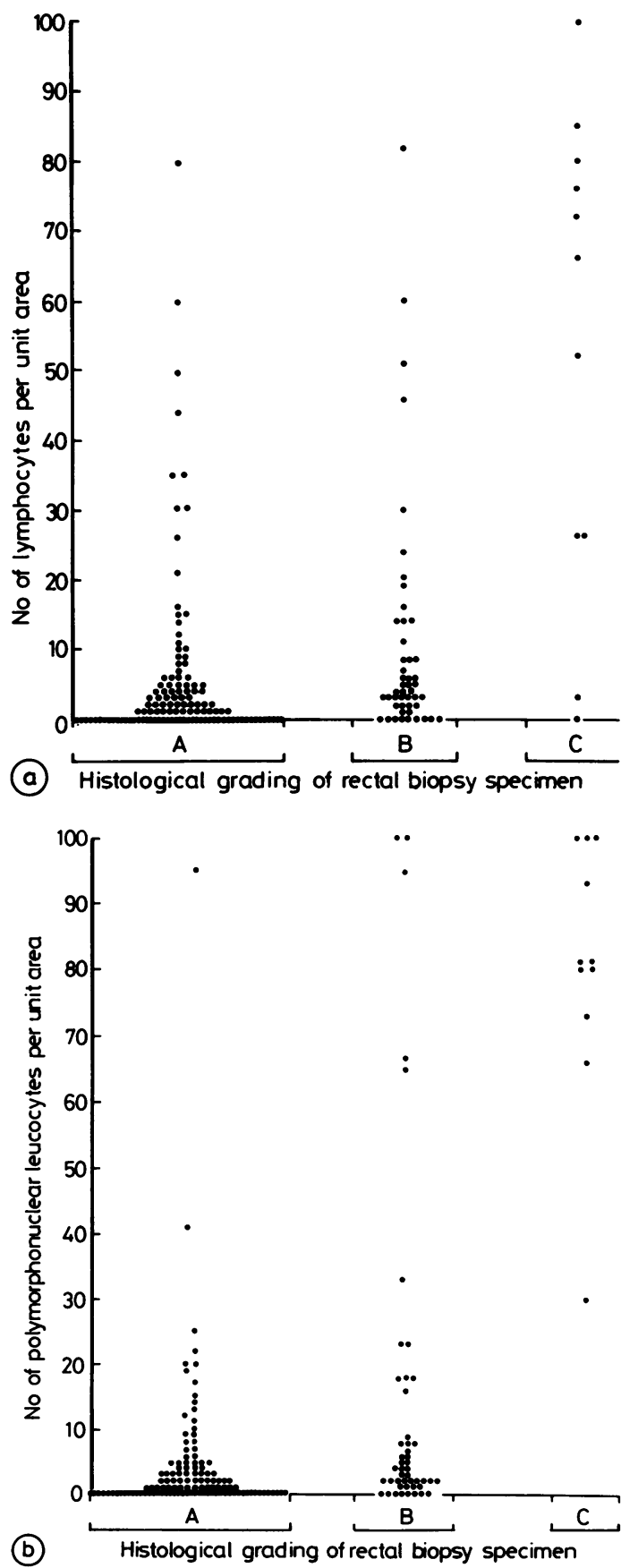

FIGURE Number of lymphocytes (a) and polymorphonuclear leucocytes (b) per unit area in rectal impression smears from patients whose rectal mucosa was histologically normal (grade A), showed an increase in chronic inflammatory cells (grade B), or showed an infective proctitis (grade C) pattern. 
TABLE $\mathrm{v}$ Median number and semi-interquartile range of polymorphonuclear leucocytes and lymphocytes per unit area of stained rectal impression smear

\begin{tabular}{|c|c|c|c|c|}
\hline \multirow[b]{2}{*}{$\begin{array}{l}\text { Histological grading } \\
\text { of rectal biopsy }\end{array}$} & \multicolumn{2}{|c|}{ Polymorphonuclear leucocytes } & \multicolumn{2}{|c|}{ Lymphocytes } \\
\hline & Median & $\begin{array}{l}\text { Semi } \\
\text { interquartile } \\
\text { range }\end{array}$ & Median & $\begin{array}{l}\text { Semi } \\
\text { interquartile } \\
\text { range }\end{array}$ \\
\hline $\begin{array}{l}\text { A: normal } \\
\text { B: chronic proctitis } \\
\text { C: infective proctitis }\end{array}$ & $\begin{array}{r}1 \\
3 \\
81\end{array}$ & $\begin{array}{l}0-4 \\
1-11 \\
65-92\end{array}$ & $\begin{array}{r}1 \\
3 \\
54\end{array}$ & $\begin{array}{c}0-6 \\
1-11 \\
24-78\end{array}$ \\
\hline
\end{tabular}

Table $V$ shows the median number of inflammatory cells per unit area of the stained smear. The null hypothesis that the median numbers of polymorphonuclear leucocytes and lymphocytes in each group were not significantly different was rejected. Analysis by the Wilcoxon test showed that the number of inflammatory cells, both lymphocytes and polymorphonuclear leucocytes, was significantly greater $(p<0 \cdot 001)$ in smears from men whose rectal changes were graded $C$ than in those from men whose rectal changes were graded A or B. There was, however, no significant difference $(p>0.05)$ in the median number of cells per unit area between smears from men whose rectal changes were graded A and B.

\section{Discussion}

The usefulness of cytology in detecting microscopically abnormal mucosa in patients with ulcerative colitis has been reported. ${ }^{4}$ In the present study, if an arbitrary dividing line of $\geqslant 25$ polymorphonuclear leucocytes per unit area is considered abnormal, then each of the 11 patients whose rectal histological changes were those of infective proctitis

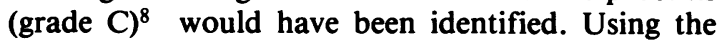
strict criteria of Watts et $a l^{4}$ for the sigmoidoscopic diagnosis of proctocolitis, the rectal mucosa appeared normal in two of these men. Unfortunately the small numbers of patients with grade $\mathbf{C}$ changes precluded a detailed comparison of the sensitivities of cytology and sigmoidoscopy in the detection of infective proctitis. Cytological smears from three men $(2 \cdot 6 \%)$ whose rectal biopsy specimens showed no histological abnormalities contained $\geqslant 25$ polymorphonuclear leucocytes per unit area (figure). The presence of large numbers of pus cells in cytology smears from patients who did not have proctitis was also noted by Watts et al, ${ }^{4}$ who suggested that these cells may have migrated from an adjacent or distant area of mucosal inflammation.

If our results are confirmed in a larger series of patients with infective proctitis, then the cytological examination of rectal mucosal secretions, with its high sensitivity and specificity, would be a valuable diagnostic test. One advantage of the method used here is that the numbers of inflammatory cells within a defined area are counted. By rolling a swab over the rectal mucosa and examining a stained smear made from this swab an indefinite area of rectal mucosa is sampled. The results obtained may then be difficult to interpret and comparisons with studies from other centres are not possible.

The failure of cytological examination of mucosal secretions to detect patients with chronic proctitis (grade B) is clearly shown in this study. Only six $(12.5 \%)$ of the 48 men with grade B rectal changes had $\geqslant 25$ polymorphonuclear leucocytes per unit area. The sigmoidoscopic appearance was abnormal in eight men, including five in whose rectal smears the number of inflammatory cells per unit area was increased above normal.

In general, the numbers of lymphocytes per unit area paralleled those of the polymorphonuclear leucocytes. Confusion in interpretation may arise if the secretions over a lymphoid follicle are sampled. ${ }^{9}$

Although patients with infective proctitis were more likely to have symptoms referable to the gastrointestinal tract, the prevalence of these symptoms in patients with chronic proctitis was not significantly higher than in men whose rectal histological changes were normal. Clearly, a diagnosis of chronic proctitis cannot be made reliably on consideration of the clinical and cytological findings. It is interesting to note that doctors working in almost $80 \%$ of STD clinics in England and Wales based a diagnosis of non-specific proctitis on only one criterion, usually the microscopic examination of a rectal smear, and in $37 \%$ of clinics the diagnosis was made by consideration of clinical features only. ${ }^{3}$

Since an organismal cause of the chronic proctitis could be found in only $18(37 \cdot 5 \%)$ of the 48 men affected, it is likely that many patients with chronic non-specific proctitis are not identified when they attend a STD clinic for routine investigation. From our data it is clear that rectal biopsy is the most sensitive method available for the diagnosis of proctitis in men who have had anal intercourse. It is well established that ulcerative colitis can be diagnosed before the characteristic sigmoidoscopic or radiological changes become evident. ${ }^{910}$ 
Our findings indicate how insensitive and nonspecific are the present widely used methods for diagnosing proctitis in STD clinics. Rectal biopsy is an invasive procedure but is rarely complicated by haemorrhage or rectal perforation. ${ }^{11}$ As chronic proctitis may be a benign and self-limiting condition (personal observation) we do not recommend rectal biopsy as part of the routine investigation of men who have had homosexual anal intercourse. The careful collection of anorectal material and faeces for microbiological examination is more important than carrying out a biopsy. Clearly pathogenic microorganisms may be present on the surface of rectal mucosa which are histologically normal. ${ }^{5}$ In research work on the aetiology and natural history of nonspecific proctitis, however, histological examination of rectal tissue should always be undertaken. To rely on the sigmoidoscopic or cytological findings is insufficient.

We thank Drs I W Smith and H Young and the staff of the department of bacteriology, University of Edinburgh, for undertaking the microbiological examination of rectal specimens. We also thank Dr $\mathbf{R}$ $\mathrm{J}$ Prescott of the department of medical statistics and computing for his help in the statistical analyses of the data.
This project was funded by the Biomedical Research Committee of the Scottish Home and $\underline{ }$. Health Department (grant No K/MRS/50/C414).

\section{References}

1. British Co-operative Clinical Group. Homosexuality and $\frac{\widehat{\oplus}}{\vec{D}}$ venereal disease in the United Kingdom. Br $J$ Vener Dis Q 1980;56:6-11.

2. Quinn TC, Corey L, Chaffee RG, Schuffler MD, Braucato FP, Holmes KK. The etiology of anorectal infections in homosexual men. Am J Med 1981;71:395-406.

3. Adler MW. Diagnostic, treatment, and reporting criteria for non-specific genital infections in sexually transmitted diseases $\vec{\omega}$ clinics in England and Wales. Br $J$ Vener Dis 1978;54:422-7.

4. Watts JMcK, Thompson H, Goligher JC. Sigmoidoscopy and $\stackrel{\mathscr{P}}{\longrightarrow}$ cytology in the detection of microscopic disease of the rectal ir mucosa in ulcerative colitis. Gut 1966; 7:288-94.

5. McMillan A, Lee FD. Sigmoidoscopic and microscopic appearance of the rectal mucosa in homosexual men. Gut 1981;22: 1035-41.

6. Dickinson RJ, Gilmour HM, McClelland DBL. Rectal biopsy in patients presenting to an infectious disease unit with diarrhoeal disease. Gut 1978; 20 : 141-8.

7. Anthonisen P, Riis P. A new diagnostic approach to mucosal inflammation in proctocolitis. Lancet 1961; ii:81-2.

8. Day DW, Mandal BK, Morson BC. The rectal biopsy appearance in Salmonella colitis. Histopathol 1978; 2:117-31. 든

9. Anthonisen P, Riis P. The cytology of colonic secretions in $\mathcal{S}$ proctosigmoidal disease. Acta Med Scand 1962;172:375-81.

10. Matts SGF. The value of rectal biopsy in the diagnosis of ulcerative colitis. $Q J$ Med 1961;30:393-407.

11. Gabriel WB, Dukes CE, Bussey HJR. Biopsy of the rectum. Br. J Surg 1951;38:401-11. 